Revista de Economia Política, vol. 34, no 2 (135), pp. 294-316, abril-junho/2014

\title{
Incerteza e não ergodicidade: crítica aos neoclássicos
}

\author{
MARCELO MALLET SIQUEIRA CAMPOS \\ TULIO CHIARINI*
}

Uncertainty and non-ergodicity: critique of the neoclassical. The starting point of this essay is to show that, in our view, the problem of the traditional economics is not in the deductive method nor the mathematical methods used, but to attribute to economic agents "power" on the future and prescribe the existence of ergodic stochastic processes in their economic analyzes. Thus, building a theory on the ground whose bases are not able to sustain a proper understanding of the world, mainstream economics has difficulties in using the modeling for establishing deductions and conclusions that help understanding the system. Thus, the logical-mathematical rigor in economic models and deduction can be used with appropriate axioms, which is not the case of mainstream economics. Our hypothesis is that the inability of the mainstream in predicting economic crisis is due to the non-recognition of some principles that best describe the dynamics of financialized contemporary capitalism, as the principles of non-ergodicity and Keynesian uncertainty.

Keywords: Uncertainty; non-ergodicity; financial crisis.

JEL Classification: E00; E02; E12.

Vivo sempre no presente.

O futuro, não o conheço.

O passado, já o não tenho.

Fernando Pessoa

\footnotetext{
* Respectivamente, Professor do IFRS, campus Bento Gonçalves. E-mail: marcelo.campos@bento.ifrs. edu.br. Analista em C\&T do INT/MCTI. E-mail: tulio.chiarini@int.gov.br. Uma versão preliminar desse trabalho foi apresentada na V Conferência da Associação Keynesiana Brasileira, São Paulo (SP), 2012, com o seguinte título: "Incerteza e não ergodicidade: ensaio a partir da crise de 2008". Submetido: 28/ junho/2012; Aprovado: 28/maio/2013.
} 


\section{INTRODUÇÃO}

Há propostas teóricas diferentes em entender tanto o surgimento quanto a dinâmica de crises econômicas. Assim, aos fatores e mecanismos que levam às crises são dados diferentes relevos e nuanças, estabelecendo interpretações muitas vezes desarmônicas. Este artigo não visa analisar e crise financeira em si, mas resgatar elementos heterodoxos para a compreensão do funcionamento da economia capitalista financeirizada a partir da constatação da incapacidade do instrumental teórico neoclássico em entender e prever o funcionamento dos mercados.

O capital não é apenas instrumento material da produção, mas também um ativo financeiro que rende juros e dinheiro (Braga, 2000) em um ambiente onde a moeda é capaz de acalmar as inquietações resultantes de incertezas futuras e os agentes a retêm em busca de liquidez. Desse modo, o capitalismo é entendido como a ordem econômica em que o dinheiro não é apenas um intermediário nas transações econômicas corriqueiras, mas a forma geral da riqueza e o objetivo final da concorrência entre os produtores (Belluzzo, 2009). Ou seja, o objetivo não é a produção para o consumo, mas sim a valorização dos capitais (Braga, 2000), mais especificamente sua valorização fictícia. Essa é, portanto, a lógica de uma economia monetária da produção definida por Keynes (1933), onde a moeda afeta motivos e decisões ${ }^{1}$ e possui dinâmica própria. Assim sendo, mudanças nas expectativas futuras e a incapacidade de prever adequadamente o desenrolar do futuro são capazes de influenciar o volume de emprego e renda e não somente sua direção.

Uma economia monetária da produção não possui ciclos predefinidos, o que implica a impossibilidade de prever seu funcionamento baseando-se em acontecimentos passados, mas pode-se entender sua dinâmica e constatar que possui movimentos de autoexpansão e valorização permanente (Tavares, 1998), isto é, o capital move-se incessantemente entre o dinheiro, os ativos financeiros e o conjunto de mercadorias, ampliando seus objetos de sua valorização (Braga, 2000). Existe, portanto, como nos ensina Marx, uma tensão entre expansão e crise do capitalismo e suas permanentes flutuações decorrem tanto da valorização produtiva quanto da valorização financeira. Assim, ao aceitar tal tensão, deve-se aceitar que o sistema econômico é complexo e se fundamenta em conceitos comumente ignorados pelo mainstream econômico, como a não ergodicidade, a irreversibilidade do tempo histórico, as incertezas, as incógnitas informacionais, a racionalidade limitada e processual (bounded rationality e procedural rationality) dos agentes, a preferência pela liquidez, as expectativas e o papel das instituições em moldar tal sistema. Alguns desses conceitos serão abordados mais enfaticamente no decorrer deste ensaio, já que são princípios fundamentais para se entender as crises. Para tanto, apresen-

\footnotetext{
1 "Money plays a part of its own and affects motives and decisions and is, in short, one of the operative factors in the situation, so that the course of events cannot be predicted, either in the long period or in the short, without a knowledge of the behavior of money between the first state and the last. And it is this which we ought to mean when we speak of a monetary economy" (Keynes, 1933, p. 408, grifos do autor).
} 
ta-se o núcleo das ideias de Keynes, apoiando-se em seus próprios trabalhos e também em alguns de seus principais intérpretes.

A teoria neoclássica tradicional, por exemplo, sustenta que a crise econômica é um evento anormal, excepcional e transitório, supondo um modelo de equilíbrio geral onde o sistema é regular e previsível no que se refere ao comportamento dos agentes econômicos². Logo, é dada ênfase à capacidade de fazer previsões (Lisboa, 1997, 1998). Os neoclássicos argumentam que a teoria não precisa ser realista, apenas capaz de fazer boas previsões, diferentemente de uma economia monetária, pois não há mecanismos que garantam que o passado sirva de guia para tomadas de decisões futuras, daí o sentido da não-ergodicidade. Mas, dentro da lógica neoclássica, por que os economistas dessa corrente não previram a crise de 2008-2009? A teoria neoclássica teria perdido sua capacidade de previsão? São miseráveis os argumentos keynesianos e minskianos que insistem na instabilidade de uma economia monetária e na não ergodicidade do mundo? Tais questões orientarão a discussão que aqui se propõe, cujo objetivo é apresentar que a teoria neoclássica, ao dispor da ergodicidade das atividades humanas e ao tratar da incerteza como risco probabilístico, é capaz de entender as crises apenas como falhas de mercado, que podem ser sanadas e evitadas.

Desse modo, nossa hipótese é de que a teoria neoclássica é incapaz de entender a dinâmica do sistema capitalista financeirizado ao supor a ergodicidade (dentre outros axiomas) e dessa forma leva a previsões que podem não refletir o verdadeiro funcionamento sistêmico da economia. Diferentemente, a possibilidade de crises é elemento central de várias abordagens teóricas não tradicionais, como a marxista, keynesiana e schumpeteriana. Inspiração para esse ensaio foi encontrada em Davidson (2012), o qual questiona se a economia é uma ciência e como foi possível que teóricos da eficiência dos mercados não previram a crise financeira que se iniciou em 2008.

O ponto de partida deste ensaio, na seção seguinte, é a apresentação de que, a nosso ver, o problema da economia tradicional não está apenas no método dedutivo, no rigor e nos métodos matemáticos, mas principalmente em atribuir aos agentes econômicos o "poder" sobre o futuro e em prescrever a existência de processos estocásticos ergódicos em suas análises econômicas. Segundo Davidson (2011, 2012), a teoria econômica deve ser entendida como uma ferramenta analítica e é perfeitamente aceitável que tenha rigor lógico-matemático em seus modelos e que a dedução possa ser utilizada para se alcançar conclusões. O problema está na formulação de certos axiomas, como será visto. Keynes $(1985$, p. 3) já advertia no prefácio da primeira edição de sua Teoria Geral que "se a economia ortodoxa está em desgraça, o erro não se encontra na superestrutura, que foi elaborada com

\footnotetext{
${ }^{2}$ Davidson (2011) argumenta que os axiomas da teoria neoclássica condicionam suas conclusões aos seus pressupostos irrealistas, a saber, os axiomas da moeda neutra, da substituição bruta e da ergodicidade.
} 
grande cuidado, levando em conta a consistência lógica, mas a falta de clareza e de generalidade das premissas".

A segunda seção trata de dois elementos fundamentais da teoria monetária da produção keynesiana: a incerteza e a não ergodicidade, elementos-chave que fizeram da Teoria Geral de Keynes um rompedor de paradigma. A terceira seção apresenta a dinâmica atual do capitalismo financeirizado, sem ter pretensão em propor uma nova leitura da crise de 2008-2009, mas de organizar as principais contribuições teóricas, que, a nosso ver, chocam-se com a teoria neoclássica. Ficará evidente que o arcabouço teórico keynesiano consegue melhor explicá-la. Finalmente, finda-se este trabalho com algumas considerações finais.

\section{DO MÉTODO}

Até os anos 1930, a visão que prevaleceu entre os economistas sobre como fazer teoria econômica foi o método hipotético-dedutivo ${ }^{3}$, que afirmava que a economia lida com um objeto complexo o qual apresenta inúmeras causalidades. Ou seja, a Economia constitui uma ciência inexata, e por isso o fato de a empiria não corroborar as previsões da teoria não implica, necessariamente, que os princípios teóricos sejam falsos, significando apenas que a teoria econômica não é capaz de prover todas as causalidades presentes nos fenômenos econômicos, apenas as mais relevantes.

Hutchison (1965) foi um dos primeiros autores a desafiar o método hipotético-dedutivo a partir do positivismo lógico, que propõe que o método científico deva partir de fatos para chegar às leis e estas então devem retornar aos fatos. A crítica realizada por Hutchison (1965) centra-se na afirmação de que a maioria dos economistas constrói suas teorias de forma errônea, por usar indevidamente cláusulas ceteris paribus e por afirmar que as leis da teoria econômica não são testáveis diretamente e nem apresentam testes empíricos em suas teorias.

A crítica de Hutchison (1965) desencadeou um efeito sobre os demais filósofos econômicos. Knight (1940), por exemplo, chegou a afirmar que Hutchison (1965) equivocou-se em não separar as ciências naturais das sociais, já que as ciências sociais são complicadas e complexas, especialmente se forem testadas. Knight (1940) não apresenta argumentos contrários à determinação de leis para a econo-

\footnotetext{
${ }^{3}$ Esse método, a despeito do nome, é um método indutivo formulado por Stuart Mill. Mill sustenta que a economia é uma ciência específica e complexa e por isso os economistas partem de premissas as quais podem ser de cunho psicológico ou de cunho técnico. As psicológicas são estabelecidas por introspecção, ou seja, pelo exame da própria psicologia, e as técnicas são obtidas por observações ou por experimentações. Por ser uma ciência complexa e por lidar com leis tendenciais, não é possível fazer experimentos controlados, já que todo fenômeno econômico lida com diversas variáveis, portanto, o economista lança mão de outras ciências baseadas no método indutivo a fim de conseguir conclusões seguras, já que foram observadas e testadas. O problema é que, mesmo assim, ainda há em jogo um conjunto imenso de variáveis influenciadoras do fenômeno econômico, por isso, deve-se utilizar cláusulas ceteris paribus para que se possa auferir alguma previsão.
} 
mia, porém, segundo ele próprio, há motivações, intenções e valores nas ciências sociais; não nas naturais. Captar regularidade do comportamento não basta; deve-se compreender o que há por detrás de suas ações.

Essa reação contra a crítica de Hutchison não teve muita repercussão, já que o positivismo lógico era a base fundamental da filosofia da economia, era o "método científico por excelência”. A reposta de Knight (1940), em última instância, causou certo incômodo, já que afirmou que a economia e as ciências sociais como um todo não se ajustam ao positivismo lógico. Knight, porém, não foi o único a demonstrar reação às críticas feitas por Hutchison. Outra crítica ressaltada consistiu no esforço em se testar, empiricamente, as proposições econômicas. Na Inglaterra e nos Estados Unidos houve empenho de alguns economistas em verificá-las de forma empírica. Posteriormente a esse esforço empírico e a metodologia de Hutchison, Machlup (1994) critica-os a partir do desenvolvimento do empirismo lógico.

Friedman (1953) elaborou a crítica mais consistente a Hutchison, desenvolvendo a metodologia da economia positiva, atraindo diversos adeptos. Por não estar num período de crise do capitalismo, como o vivido por Hutchison, Friedman vivencia certa "atmosfera de confiabilidade" em toda a teoria econômica, já que a mesma apresentava aceitáveis índices de desemprego, inflação e crescimento. Em sua obra The Scope and Method of Political Economy Friedman (1953) apresenta cinco capítulos a fim de expor toda a sua teoria.

Primeiramente, Friedman (1953) divide a economia em dois ramos distintos: economia positiva (como é?) e economia normativa (como deve ser?), e, a partir de então, ele explica a relação existente entre a economia positiva e a normativa, cuja relação apresenta certa confusão inevitável (Friedman, 1953, p. 5). A economia positiva independeria de qualquer posição ética particular e/ou julgamentos normativos. Assim como afirma Neville Keynes (1891, apud Friedman, 1953), ela é responsável em lidar com “o que é”, não com "o que deve ser” e seu objetivo consiste em gerar um sistema que possa ser capaz de criar previsões corretas, ou seja, o objetivo da economia positiva é simplesmente preditivo; ou seja, uma ferramenta para prever os acontecimentos e funcionamento dos mesmos de forma correta, pouco importando se explica o mundo e se descreve os acontecimentos tais como eles são. O objetivo principal da economia positiva seria desenvolver "teorias" ou "hipóteses" capazes de levar a previsões válidas sobre fenômenos que ainda não foram observados (Friedman, 1953, p. 7).

Ao realisar uma análise mais aprofundada sobre a economia positiva, Friedman (1953), verifica que seu objetivo máximo é desenvolver "teorias" cuja previsibilidade sobre novos fenômenos e acontecimentos seja significativa.

Dados tais objetivos da teoria, aquela teoria que faz previsões corretas seria, portanto, uma boa teoria. A validade de uma hipótese confirma-se a partir da comparação de suas previsões com a experiência. Assim sendo, uma hipótese será rejeitada caso suas previsões se contradigam com a realidade; e, se isso ocorrer, deve-se buscar outra hipótese capaz de fazer previsões suficientemente corretas de novos eventos, os quais serão testados da mesma forma seguindo a regra anterior. 
Se duas teorias fazem previsões corretas, ambas são boas. Há, então, uma arbitrariedade em escolher a "melhor". Friedman (1953) sugere que uma boa regra geral seria seguir o critério da simplicidade. Assim sendo, deve-se aceitar aquela teoria que seja mais simples e frutífera, ou então aquela que tem um campo de previsão mais abrangente. Por isso a validade ou não de uma hipótese não constitui critério único para a escolha de uma ou de outra hipótese alternativa. Para Friedman (1953), somente o sucesso da previsão é suficiente para aceitar uma teoria, independentemente da concreticidade de seus pressupostos. Se uma teoria não se descreve realistamente, mas provê satisfatoriamente seus propósitos, ou seja, leva a previsões acuradas o bastante, ela por si só deve ser aceita.

A questão da abordagem instrumentalista se justifica por sua capacidade de gerar previsões e é, portanto, assim apresentada:

Utiliza-se, então, o modelo cujas previsões sejam melhor corroboradas pelos dados existentes. É irrelevante se as hipóteses utilizadas pelo modelo são inconsistentes com alguma observação empírica ou mesmo as hipóteses utilizadas por outros modelos que estudam problemas distintos. [...] A validade do modelo depende apenas de sua eficiência preditiva. (Lisboa, 1998, p. 119)

Mesmo que haja uma aparente falsidade das hipóteses, pode ser que elas sejam plausíveis devido à conformidade de suas implicações com suas observações, ou seja, uma hipótese é mais ou menos atrativa do que outra não porque ela é mais ou menos realista do que a primeira, mas porque é parte de uma teoria geral que pode ser aplicada a uma variedade maior de fenômenos (Friedman, 1953). Assim, Friedman (1953) conclui que não se pode testar uma teoria pelo realismo de suas hipóteses, cujas principais funções em uma teoria, apesar de certa "confusão", são: a) descrever ou apresentar uma teoria, b) facilitar um teste indireto de uma hipótese através de suas implicações e c) ser um meio conveniente de especificar as condições pelas quais é esperado uma validade da teoria. Friedman (1953) prossegue, afirmando que uma hipótese pode apresentar duas partes: uma conceitual e abstrata; e outra como um conjunto de regras que define a classe de fenômenos em que os modelos podem corresponder ao mundo real e especificar as relações correspondentes entre as variáveis ou entidades nos modelos e nos fenômenos observáveis.

Falou-se o tempo todo em previsões, mas o que vem a ser uma previsão? Previsão, segundo Friedman (1953), nada mais é do que qualquer consequência deduzida de uma teoria (previsão = implicação). Friedman (1953) não explica o porquê de aceitar que a economia tem por objetivo fazer previsões e não meramente descrever as consequências de ações. Ele aceita tal fato como um pressuposto e não é capaz de explicar a razão disso. As previsões podem ser testadas se forem eliminados os fatores de distúrbio que as influenciam, sendo que muitas vezes é preciso aceitar as evidências experimentais/empíricas de tal evento. Tais evidências são 
vitais em dois diferentes estágios - em construir as hipóteses e em testar sua validade - e são relacionados em dois diferentes aspectos:

In first place, the particular facts that enter at each stage are partly an accident of the collection of data and the knowledge of the particular investigator. The facts that serve as a test of the implications of a hypothesis might equally well have been among the raw material used to construct it, and conversely. In the second place, the process never beings from scratch; the so-called "initial stage" itself always involves comparison of the implications of an earlier set of hypotheses with observation [...]. (Friedman, 1953, p. 13)

A inabilidade de conduzir 'experimentos controlados' não reflete uma diferença básica entre as ciências sociais e as ciências físicas (Friedman, 1953). Com tal argumentação, levantou-se a crítica à afirmação de Hutchison de que a economia não é uma ciência que apresenta um método adequado, já que se utilizam cláusulas ceteris paribus.

No experiment can be completely controlled, and every experience is partly controlled, in the sense that some disturbing influences are relatively constant in the course of it. [...] Thus the inability to conduct experiments [in economics] is not a fundamental obstacle to testing hypotheses by the success of their predictions. (Friedman, 1953, pp. 10-11)

Embora a metodologia desenvolvida por Friedman (1953) incorra em alguns pontos passíveis de críticas, a mesma fez-se bastante valorosa e, principalmente, por marcar um avanço no pensar sobre o modo como os economistas desenvolvem suas pesquisas. No entanto, foi criticada diretamente por Hausman (1992), que não aceita que se deva considerar apenas a previsibilidade das hipóteses.

Os economistas devem, conforme destaca Hausman (1992), levar em conta os fatores que possam influenciar a previsibilidade da hipótese, já que a ciência econômica é uma ciência complexa por natureza. Além disso, a distinção utilizada por Friedman (1953) entre os pressupostos e previsões/implicações é muito tênue, assim, se um pressuposto for falso, ele gerará uma previsão falsa, e desta forma a teoria não deverá ser considerada boa teoria, já que não levará a previsões corretas ${ }^{4}$.

Apesar de todos os problemas de sua metodologia, Friedman apresenta uma maneira persuasiva de explicar seu ponto de vista, o qual prosperou por longo tempo entre os economistas (Hausman, 1992). Lançando mão de uma linguagem

\footnotetext{
${ }^{4}$ Outra crítica apontada por Hausman (1992) diz respeito às considerações que Friedman (1953) faz em relação ao que seria um pressuposto realista. Friedman (1953) por diversas vezes "joga" com o sentido da palavra realista, podendo este ser tratado como abstrato ou falso: um fato seria irreal, pois é abstrato, ou seja, não é capaz de produzir a realidade. Assim, toda teoria abstrata é irreal. Porém, utiliza-se irreal com sentido de falso, o que vai contra a realidade.
} 
simples e rica em exemplos ainda mais elucidativos, a Metodologia da Economia Positiva, em última instância, sugere que fazer economia significa fazer modelos que apresentam um grau de previsibilidade elevado.

Essas considerações se enquadram nas extensas discussões que tem ocorrido quanto à metodologia no campo das ciências sociais e da economia de uma maneira mais específica. Blaug (1985) apresenta contribuições semelhantes ao defender a ideia de falseacionismo como critério qualitativo para se fazer previsões e mesmo para se definir o científico no universo econômico.

A complexidade dos problemas econômicos que tem surgido na atualidade tem levado a uma abertura cada vez mais acentuada na cláusula ceteris paribus tornando cada vez mais necessário o controle e a compreensão de uma gama maior de variáveis que compõem o comportamento dos agentes. Neste ínterim, muitos esforços têm sido feitos de maneira a trazer maior sintonia na relação normativo-preditivo.

Para Davidson (2012), o problema da economia tradicional não está no método dedutivo, no rigor e nos métodos matemáticos ${ }^{5}$, mas em assumir que os agentes econômicos têm conhecimento sobre o futuro e em impor a existência de processos estocásticos ergódicos nas análises econômicas, a fim de transpor a political economy do âmago da história para o âmago da ciência, transformando-a em economics, ou seja, uma tentativa de colocar a economia no patamar das "ciências duras" como a física.

This ergodic axiom assumes the economic future is already predetermined. The economy is governed by an existing ergodic stochastic process. One merely has to calculate probability distributions regarding future prices and output to draw significant and reliable statistical inferences [information] about the future. Once self-interested decision makers have reliable information about the future, their actions on free markets will optimally allocate resources into those activities that will have the highest possible future returns thereby assuring global prosperity. (Davidson, 2012, n.p.)

O axioma da ergodicidade impõe a condição de que o futuro é predeterminado por parâmetros existentes, consequentemente, o futuro pode ser previsto pela análise do passado e dados de mercados correntes para obter uma distribuição de probabilidade que possa gerir eventos futuros (Davidson, 2012).

\footnotetext{
5 "Outra tendência que parece definida quando se olha o passado recente da economia é a opção por uma abordagem formal, voltada para a construção de modelos e fortemente associada ao uso de uma linguagem matemática. Os incomodados podem retirar-se sob protestos, mas o fato é que as novas gerações tendem a entender e apreciar esse tipo de linguagem, porque nela aprenderam a comunicar-se. Que a retirada do velho estilo não implique a perda da capacidade de reflexão e o espírito crítico, é tudo que se pode desejar" (Bianchi, 2011, p. 135).
} 
In other words, if future events are assumed to be generated by an ergodic stochastic process (to use the language of mathematical statisticians), then the future is predetermined and can be discovered today by the proper statistical probability analysis of past and today's data regarding market "fundamentals". If the system is nonergodic, calculated past and current probability distributions do not provide any statistically reliable estimates regarding the probability of future events. (Davidson, 2012, n.p.)

Ademais, um ponto fundamental é como se dá a tomada de decisão do agente econômico nesse ambiente ergódico. Nesse sentido, suas decisões são estimativas calculadas sobre o comportamento ex ante de variáveis que lhes interessam, baseadas em cálculos probabilísticos, ou seja, em análises de risco (Ferrari Filho \& Araújo, 2000).

O erro dos agentes, ao formularem tais cálculos probabilísticos para prever eventos futuros, deve-se às falhas de mercado, como a informação assimétrica, conforme defendem os novos-keynesianos. Dessa forma, devido à falta de informações corretas, há uma distribuição de probabilidade equivocada dos eventos futuros, consequentemente o mercado não se comporta de maneira eficiente. Essa é a justificativa dos possíveis erros nas previsões para os neoclássicos que continuam com sua "fé cega" na suposta capacidade de regulação dos mercados, a qual, como afirma Mazzucchelli (2008), serve como um dogma que supõe a racionalidade imanente que garante o funcionamento ótimo da economia.

Essa teoria econômica ensinada e praticada nos últimos 40 anos, por ser coerente e bem fundamentada (sic!), foi amplamente utilizada em modelos abstratos em Wall Street, porém, não lida com o tempo, com incertezas, sem falar do financiamento dos direitos de propriedade sobre bens de capital e dos investimentos (Minsky, 2008). Além, disso, apesar de sua estrutura lógica elegante (Minsky, 2008, p. 43), a teoria econômica atual (síntese neoclássica) "falha em nos explicar como uma crise financeira pode emergir num contexto de funcionamento normal da economia" (Minsky, 2008, p. 43) e não oferece uma base de sustentação de resultados coerentes a partir das economias de mercado descentralizadas e por que razões uma economia mostra-se suscetível às crises e em outros não.

Diferentemente, Keynes embasa sua teoria no conceito de incerteza sobre o futuro o qual requer um processo estocástico não ergódico, abrindo caminho para uma ruptura em entender a dinâmica econômica. Não é por meio de análises estatísticas ou de crenças baseadas em acontecimentos passados que os agentes deliberam suas tomadas de decisões quanto ao futuro (Ferrari Filho \& Araújo, 2000).

De acordo com Davidson (2012), os agentes “racionais" sabem que eles não conhecem adequadamente o futuro e isso é um emento essencial em entender a dinâmica de operação do sistema capitalista, o que fora proposto de forma adequada por Keynes. 
Para Keynes, o fato dominante da vida é a incerteza fundamental e incontornável que cerca o futuro. [...] Keynes foi um ácido crítico das teorias ortodoxas de economia, que assumiam que os agentes econômicos habitam um mundo onde tudo é previsível, seja com certeza, seja probabilisticamente. (Carvalho, 2003, p. 176).

Keynes defendia que a probabilidade é uma relação lógica entre dois conjuntos de proposições, cujas relações são resultadas a partir do pensamento e do entendimento de mundo dos agentes e não como uma relação independente do pensamento humano, por isso o modelo de Keynes pode ser identificado com o arcabouço construtivista de probabilidade incomensurável (Palley, 1993).

A discussão sobre incerteza e não ergodicidade keynesiana será retomada na próxima seção, no entanto, vale já ressaltar que incerteza, para Keynes, ocorre quando não há base para calcular alguma probabilidade ${ }^{6}$, ou seja, é improvável que seja modelada de forma determinística. Assim, mudanças de pontos de vista sobre o futuro, devido à incerteza, são capazes de influenciar a dinâmica econômica, sendo essa uma característica essencial de uma economia monetária.

O objetivo da discussão proposta anteriormente é mostrar a suposta capacidade do método neoclássico de fazer previsões, a qual se apresenta como praticante do método científico. No entanto, a corrente neoclássica pratica uma das possíveis correntes metodológicas, e não apresenta a existência de questionamentos a respeito da validade de método (Lisboa, 1997, 1998).

\section{DA INCERTEZA E DA NÃO ERGODICIDADE}

Uma das limitações da teoria neoclássica é ignorar o papel que a incerteza exerce na economia e supor um ambiente ergódigo. De acordo com North (2005), a maioria dos economistas não se questiona a respeito dos fundamentos da teoria econômica tradicional, principalmente a respeito da incerteza e da ergodicidade. Não obstante, costumam tratar a incerteza como algo incomum, sendo a condição de certeza (que garante uma modelagem matemática elegante) tratada como o usual da economia. Mas a incerteza é justamente o padrão, e, para lidar com ela, os seres humanos desenvolvem determinadas estruturas.

Can we, therefore, predict what it will be like tomorrow? The answer is that the time horizon for such prediction to be accurate is very short. The changes in the environment that we make today create a new and in many cases novel environment tomorrow - novel in the sense

\footnotetext{
6 "There is no scientific basis on which to form any calculable probability whatever. We simply do not know" (Keynes, 1937, p. 214).
} 
that we have no historical experience that prepares us to deal with it. (North, 2005, p. 20)

À medida que os seres humanos reduziram as incertezas relacionadas ao ambiente, aumentaram a complexidade do ambiente humano. Parte do entendimento limitado se deve à inexistência de "power laws" nas ciências humanas, como nas ciências físicas. A principal razão é a natureza não ergódiga do mundo, que se altera continuamente, abrindo espaço para o conceito de incerteza e seu papel ao afetar motivos e decisões.

De acordo com Davidson (1991) existem três ambientes mutuamente exclusivos onde podem ocorrer as decisões econômicas: 1) "ambiente de probabilidades objetivas”, ou seja, acredita-se que o passado é estatisticamente confiável, não apresenta nenhum viés, e serve como guia para o futuro; 2 ) "ambiente de probabilidades subjetivas”, isto é, a probabilidade subjetiva, de cada agente individual, sobre as perspectivas futuras governa resultados futuros no momento da escolha; e 3) "ambiente verdadeiramente incerto", ou seja, independentemente de a ocorrência das frequências relativas objetivas poderem ser confirmadas no passado ou que as probabilidades subjetivas existam hoje, o agente acredita que durante o tempo entre $o$ momento de escolha e do resultado mudanças não previstas podem ocorrer; há uma verdadeira ignorância do futuro. Esse último é o ambiente keynesiano de incerteza não mensurável (riscos imprevisíveis), onde somente a moeda pode acalmar inquietações dos agentes, por causa de suas propriedades especiais ${ }^{7}$ (Carvalho, 1996).

Entretanto, a distinção entre risco e incerteza é anterior aos trabalhos de Keynes. Para Knight (1921), incerteza é a condição para a qual não existe uma distribuição de probabilidade associada, ao contrário do risco, para o qual esta distribuição de probabilidade pode ser conhecida. De acordo com North (2005), a condição usual de certeza permite uma formalização matemática elegante ${ }^{8}$. Risco é objetivo, incerteza é subjetiva (Knight, 1921). No entanto, alguns neoclássicos insistem em confundir risco com incerteza: "Probabilidade não é uma propriedade do objeto, mas apenas uma forma de expressar a incerteza de um agente sobre um evento particular" (Lisboa, 1997, p. 21).

Lawson (1988) propôs uma taxonomia bidimensional construída a partir da divisão entre probabilidade comensurável e incomensurável e conhecimento construtivista e realista, como demonstrado no Quadro 1 abaixo:

\footnotetext{
${ }^{7}$ De acordo com Keynes (1985), a moeda apresenta duas propriedades fundamentais: a) elasticidade de produção da moeda é igual a zero, já que sua oferta é fixa e é determinada pela autoridade monetária; b) a elasticidade de substituição é igual, ou quase igual, a zero, "o que significa que, quando o seu valor de troca sobe, não aparece nenhuma tendência para substituí-la por algum outro fator [...]” (Keynes, 1985, p. 162).

${ }^{8}$ No entanto, a maior parte das alterações importantes na história da humanidade não foi prevista, nem seus desdobramentos antecipados.
} 
QUADRO 1: Taxonomia de Lawson

\begin{tabular}{|c|c|c|}
\hline & $\begin{array}{c}\text { Probabilidade como construção } \\
\text { do conhecimento } \\
\text { (conhecimento construtivista) }\end{array}$ & $\begin{array}{c}\text { Probabilidade como objeto } \\
\text { do conhecimento } \\
\text { (conhecimento realista) }\end{array}$ \\
\hline $\begin{array}{c}\text { Incerteza como } \\
\text { situação de probabilidade } \\
\text { comensurável }\end{array}$ & $\begin{array}{c}\text { Friedman/Savage } \\
\text { (probabilidade subjetiva) }\end{array}$ & $\begin{array}{c}\text { Muth / Lucas } \\
\text { (probabilidade objetiva) }\end{array}$ \\
\hline $\begin{array}{c}\text { Incerteza como } \\
\text { situação de probabilidade } \\
\text { incomensurável }\end{array}$ & Keynes \\
\hline
\end{tabular}

Fonte: Baseado em Lawson (1988).

A probabilidade apresenta duas naturezas: a) probabilidade entendida como "objeto do conhecimento" no sentido de ser "descoberta", "aprendida" como parte da realidade externa; b) probabilidade como "tipo de conhecimento", ou seja, como uma construção que não tem existência fora do conhecimento social (Palley, 1993). Pode-se identificar quatro quadrantes e Lawson (1988) associa cada um deles com diferentes pesquisadores, como demonstrado no Quadro 1. No quadrante de Friedman/Savage as probabilidades dos agentes são estimadas com base em fatores pessoais (sentimentos e crenças), o que os torna "construtivistas" e não realistas. Nesse arcabouço as probabilidades atribuídas pelos agentes aos resultados potenciais possuem interpretação construtiva enquanto o processo de tomada de decisão dos mesmos agentes (maximização da utilizada/lucro esperado) é objetivo, ou seja, independente do contexto social (Palley, 1993).

Para Keynes, a diferença estaria na incomensurabilidade da incerteza, já que também os agentes seriam "construtivistas".

For Friedman and Savage the nature of the construction is that agents' probability estimates are based on factors including purely private feelings and beliefs, and it is this that makes them constructivists rather than realists. Keynes' constructivism is epistemologically more radical, since he argued that probability statements are simply logical relations between two sets of propositions, where these relations are a feature of the way we think about the world rather than a feature of some real world independent of human thought. (Palley, 1993, s.n.)

Desse modo, a taxonomia proposta por Lawson (1988) melhor descreve as possibilidades teóricas encontradas na literatura do que aquela proposta por $\mathrm{Da}$ vidson (1991).

Uma economia ergódiga é aquela na qual a estrutura fundamental subjacente da economia é constante, e, portanto, timeless. Mas o mundo no qual vivemos não é ergódico, pois a incerteza do futuro econômico requer que o sistema seja gerado por um processo estocástico onde não é possível calcular distribuição de probabilidades.

Um processo ergódico estocástico significa que as médias calculadas no passado não são diferentes (ao menos de maneira persistente) do futuro (Davidson, 
1991). Para Samuelson (1969, apud Davidson, 1991), a hipótese da ergodicidade é essencial para uma economia científica9 .

If social process were ergodic [...] trial and error could lead agents to identify gradually all the necessary data to orient their decisions. Ergodicity, however, demandas replicability, which means that processes should be time-independet. (Carvalho, 1992, p. 62)

Ergodic processes can be thought of as "risky" processes moving through time, and in which uncertainty is measurable through the rules of standard probability theory: non-ergodic processes refer to processes moving through time with immeasurable uncertainty, and for which probability statements are not applicable. (Palley, 1993, s.n.)

A rejeição dos axiomas da teoria neoclássica forma a base do novo paradigma de uma economia monetária da produção como propôs Keynes, que propõe axiomas muito menos restritivos a respeito do comportamento humano, conforme será exposto na próxima seção.

O que apenas desejamos lembrar é que as decisões humanas que envolvem o futuro, sejam elas pessoais, políticas ou econômicas, não podem depender da estrita expectativa matemática, uma vez que as bases para realizar semelhantes cálculos não existem e que o nosso impulso inato para a atividade é que faz girar as engrenagens, sendo que a nossa inteligência faz o melhor possível para escolher o melhor que pode haver entre as diversas alternativas, calculando sempre que se pode, mas retraindo-se, muitas vezes, diante do capricho, do sentimento ou do azar. (Keynes, 1985, pp. 170-171)

Embora crises de origem financeira sejam recorrentes na história, como mostra Galbraith (1991), a distância temporal entre uma e outra faz com que boa parte dos indivíduos que observaram o episódio anterior não esteja mais "no mercado" no episódio seguinte. Isto faz, por um lado, com que, mesmo que haja uma probabilidade objetiva de ocorrência de crise, os indivíduos percebam esta possibilidade de maneira diferente ${ }^{10}$. Por outro lado, existe também todo tipo de informações

\footnotetext{
${ }^{9}$ Davidson (1991) enfatiza o desejo de Samuelson de remover a economia do reino da história, mantendo-a no "reino da ciência". De maneira semelhante, Solow (1985, p. 328), ao reconhecer a complexidade dos sistemas econômicos e constatar que a economia é um processo não estacionário, lamenta: "Unfortunately, however, economics is a social science". Se as séries econômicas não são estacionárias, isso implica que o ambiente econômico não é constante e homogêneo ao longo do tempo, portanto, ocorre a rejeição lógica ao axioma da ergodicidade. "Uma vez que a ergodicidade é uma condição necessária e suficiente para uma realidade externa predeterminada e imutável, tudo indica que os dados empíricos entram em conflito com o axioma fundamental ergódico da teoria macroeconômica dominante" (Davidson, 2011, pp. 173-174).

${ }^{10} \mathrm{O}$ conceito de racionalidade substantiva (em contraposição à racionalidade objetiva, utilizada pelos
} 
imprevisíveis sobre o futuro, que de alguma maneira impactam nos mercados financeiros e na economia real.

Outro problema existente decorre do horizonte temporal levado em conta nas séries estatísticas. Dependendo do número de anos observados, crises são incluídas ou não nos modelos. Ferguson (2008) descreve o caso da falência do fundo LTCM, onde seus gestores, Merton e Scholes, economistas agraciados com o Prêmio Nobel, foram incapazes de antever modificações no mercado, como a causada pela crise da Rússia. Galbraith (1991), ao listar fatores comuns nas crises financeiras, aponta que a memória financeira costuma ser breve, e desastres financeiros são facilmente esquecidos.

\section{A CRISE SOB A ÓTICA DA FINANCEIRIZAÇÃO}

Carvalho (1989), a partir dos trabalhos de Keynes, define a economia em cinco axiomas. A apresentação desses axiomas é importante para se entender a dinâmica de uma economia monetária de produção. São eles (1) axioma da produção: o objetivo da firma é obter mais dinheiro a partir da produção (D-M-D' no esquema marxista), ou seja, "acumular dinheiro é o objetivo 'real' das firmas que operam numa economia monetária” (Carvalho, 1989, p. 183). Nesse ponto é possível retomar as ideias marxistas de que a produção capitalista não visa à satisfação das necessidades dos produtos ou da população em geral, mas a produção pela própria produção, continuamente valorizando o capital, mantendo seu caráter contraditório:

[...] O motivo que impele e o objetivo que determina o processo de produção capitalista é a maior expansão possível do próprio capital, isto é, a maior produção possível de mais-valia, portanto, a maior exploração possível da força de trabalho.

[...] A circulação de dinheiro como capital [...] tem sua finalidade em si mesma, pois a expansão do valor só existe nesse movimento continuamente renovado. Por isso, o movimento do capital não tem limites. (Marx, [1867] 2002, pp. 183, 384)

O resultado final do processo D-M-D', como adverte Marx, é a troca de dinheiro por dinheiro D-D', ou seja, "dinheiro que se dilata, dinheiro que gera dinheiro” (Marx, [1867] 2002, p. 185).

O segundo axioma proposto por Carvalho (1989) é (2) o da dominância estratégica (também chamado de axioma da decisão): há uma assimetria fundamental de poder dos agentes com dominância das firmas, histórica e socialmente determinado, ou seja, "o poder de decisão sobre os processos econômicos não é distribuído de forma igualitária (Carvalho, 1989, p. 183); (3) axioma da inexistên-

neoclássicos), proposto por Simon (1986), ajuda a compreender comportamentos distintos entre os que passaram e os que não passaram por determinada situação. 
cia de pré-conciliação (chamado por Carvalho (1992) de princípio da coordenação): não há mecanismos ex ante que se configurem ex post, ou seja, a "coordenação entre produção e consumo só pode ocorrer a posteriori (Carvalho, 1989, p. 183); (4) axioma da irreversibilidade do tempo e da incerteza (Carvalho (1992) divide esse axioma em dois princípios: princípio da temporalidade e princípio da não ergodicidade): o tempo é unidirecional e flui do passado para o futuro, não havendo reversão de decisões já efetuadas. Carvalho (1992) afirma que o princípio da temporalidade diz que a produção leva tempo e é meramente uma atividade especulativa e o princípio da não ergodicidade versa sobre a irreversibilidade do tempo das decisões. Finalmente, (5) princípios das propriedades da moeda, ou seja, elasticidade de produção e substituição próximas de zero.

Esses princípios (axiomas) ajudam a entender a economia keynesiana e a dinâmica de uma economia monetária de produção, onde crises são intrínsecas ao sistema, diferentemente da lógica do mainstream ao tratar a crise como uma "espécie de enfermidade estacionária” (Vasapollo \& Arriola, 2010) a qual requer como remédio, atuações contingenciais para recolocar o sistema de volta a sua dinâmica natural rumo ao pleno emprego. A partir dessa ponderação teórica é possível entender a construção do capitalismo contemporâneo, como será exposto nos próximos parágrafos.

O processo de financeirização ${ }^{11}$ é historicamente datado, correspondendo ao período do capitalismo material concreto - posterior a decadência do keynesianimo em face do transe estrutural que teve seu estopim na década de 1970 - onde os mercados financeiros, instituições financeiras e a elite financeira passam a ter influência sobre as políticas econômicas e, sobretudo, sobre o resultado econômico (Palley, 2007). De acordo com Marques e Nakatani (2009), a dominância e o desenvolvimento do capital fictício ${ }^{12}$ foi resultado de vários fatores, dentre os quais, pode-se destacar o papel assumido pelos Estados Unidos e a Inglaterra no processo de desregulamentação financeira e a adoção de políticas voltadas à centralização dos fundos não reinvestidos tanto de empresas quanto das poupanças das famílias.

Since the 1970s, economist and government policymakers have buried and almost forgotten Keynes's economic ideas and philosophy. Led by Milton Friedman and his colleagues at the University of Chicago, the ideas of the economics profession were recaptured by a free market, laissez-faire ideology. The public and government policymakers were educated in the classical economic ideas that only two things had to be done to promote economic progress and prosperity: (1) end the era of

\footnotetext{
${ }^{11}$ A financeirização implica uma ampla mudança na relação entre o setor "financeiro" e o setor "real" da economia. Teria sido identificada inicialmente por Arrighi ao analisar as ondas longas de desenvolvimento econômico no capitalismo global (Stockhammer, 2012).

${ }^{12}$ De acordo com Marques e Nakatani (2009), existem três formas de capital fictício apresentador por Marx no livro III de O Capital: capital bancário, dívida pública e o capital acionário. Marques e Nakatani (2009) adicionam a esses os derivativos.
} 
big government [...] and (2) liberalize markets from all the government rules and regulations that had been installed [...]. (Davidson, 2009, p. 3)

Há um aumento significativo de investimentos em ativos financeiros e uma redução da acumulação de ativos instrumentais (Stockhammer, 2000; Palley, 2007); é o momento de auge do capital que se valoriza a si mesmo, sem estar necessariamente vinculado à dinâmica produtiva (sem contrapartida de atividade real), mas à esfera financeira (Aglietta, 1998, 2004). Apesar de não estar imprescindivelmente vinculado à esfera produtiva, o desenvolvimento de capital fictício não exprime ganhos ilusórios, uma vez que, de fato, enriquece seus proprietários, contudo, tais ganhos fictícios não se mantêm de modo indefinido (Mollo, 2011).

A autonomização do capital-dinheiro sob a forma de capital a juros e a correspondente expansão do sistema de crédito são os elementos que permitem entender a centralização/concentração do capital e a fusão entre os bancos e a indústria (Belluzzo, 2009). O sistema de crédito permite a acumulação de capital muito além das possibilidades de cada capital industrial e, ao mesmo tempo, torna concreta a ocorrência de crises de realização e de superprodução (Belluzzo, 2009). É exatamente o crédito que possibilita o investimento sem poupança prévia e pode compor as decisões de alocação de dinheiro em outras formas de riqueza que não a produtiva. É exatamente a preferência pela liquidez dos agentes e a decisão de investimento em ambientes de incerteza que faz com que a economia flutue continuamente, intensificando a própria incerteza.

No capital financeiro, portanto, em suas diferentes modalidades, encontra-se o cerne do capitalismo contemporâneo. Seu conceito segue a proposição de Hilferding (1985), o qual afirma que no capital financeiro aparecem unidas, na sua totalidade, todas as formas parciais de capital e partir de uma ligação estrutural e orgânica (capital industrial, entendido na forma lucro somado ao capital bancário, entendido na forma juro). É possível entendê-lo também como a fusão do capital mercantil, produtivo e bancário. O capital financeiro não é demoníaco e sua função é centralizar, mobilizar e redistribuir massas de capital monetário, fluidez, mobilidade de capital, dando potencialidade do desenvolvimento tanto do D-D' quanto to D-M-D'.

De acordo com Belluzzo e Tavares (1980) os grandes bancos que participam da constituição e da gestão do capital das grandes empresas estão interessados na supressão da concorrência entre elas, porém, ao fazer isso, estimulam a busca de novos mercados, gerando um acirramento da rivalidade entre os blocos de capital e originam a internacionalização crescente da concorrência intercapitalista.

Contemporaneamente, a finança dita as regras do jogo econômico no que tange a renda, emprego e macroeconomia, e influi o comando sobre a sua própria dinâmica (Duménil \& Lévy, 2003), por isso se diz que a "Macroeconomia da Riqueza Financeira" opera simultaneamente à "Macroeconomia da Renda e do Emprego". Além disso, registra-se a financeirização de agentes normalmente não-financeiros como as firmas (Aglietta, 2004; Stockhammer, 2010), as quais deixam de ter como objetivo primordial somente a maximização de lucros como propunha a teoria microeconômica tradicional, passando a discutir os interesses dos proprietários (acionista, shareholders) e integra-os à firma dominada pelas finanças (Dal- 
lery, 2009); há, portanto "a separação da propriedade e da gestão [...] [modificando o controle e a administração da empresa, a qual] reforçou a propriedade capitalista através de sua financeirização e de sua institucionalização" (Duménil \& Lévy, 2003, p. 33). O capitalismo dirigido pelas finanças disseminou sua lógica inexorável do mercado voltado para a maximização do valor aos acionistas por todos os cantos do planeta (Guttmann, 2008).

$\mathrm{O}$ intuito da firma, logo, é maximizar a taxa de retorno sobre o patrimônio líquido, seja através de investimentos capazes de aumentar a sua atividade produtiva, ou através da valorização fictícia de seu patrimônio em mercados borsáteis, mantendo a plena liquidez de suas aplicações. Desse modo, busca-se aumentar os pagamentos na forma de dividendos aos proprietários e recompor o estoque de ações através da compra das mesmas para aumentar artificialmente o seu valor de mercado. Essa dinâmica distingue uma alteração no comportamento dos agentes que deixam de administrar seus ativos em longo prazo, passando a conferir-lhes um horizonte de curto prazo, auferindo ganhos patrimoniais e a manutenção da liquidez dos mesmos, priorizando o crescimento externo em vez do crescimento interno da empresa (Fracalanza et al., 2009).

Notavelmente, o que se tem verificado é que esse deslocamento de objetivos empresariais veio acompanhado de menores taxas de investimentos produtivos das firmas juntamente com um aumento de suas dívidas, ou seja, aumento da alavancagem $^{13}$. Em outras palavras, as empresas têm incorrido em empréstimos externos para recomprar suas ações a fim de aumentar o valor do acionista, o que faz do endividamento crescente uma característica pronunciada do processo de financeirização (Stockhammer, 2010). Para tanto, passou-se a ter crédito bancário permissivo e a necessidade de mercados financeiros extensos, exatamente onde se forma um locus de valorização fictícia (Chesnay, 2003), representado por capitais inexistentes, negociáveis como verdadeiras mercadorias e, justamente por não terem lastro em produção real, seu valor flutua (cai ou sobe) independentemente do valor do capital real (Marx, 1985). Portanto, o patrimônio financeiro possui caráter fictício. As finanças têm um papel de superioridade, não neutro, muitas vezes subordinando a esfera produtiva real. A valorização da riqueza financeira vem preponderando sobre a produtiva, sem impedi-la, no entanto expandindo-se a velocidades superiores e produzindo instabilidade econômico-financeira estrutural (Braga, 2009).

Vale ressaltar que uma "economia financeirizada" - necessariamente uma economia monetária, portanto à mercê de todas as sortes intrínsecas ocasionadas pelas contradições imanentes dessa economia, id est, instável por natureza ${ }^{14}$ (Minsky, 2008) - tornou-se possível devido a certos acontecimentos dinâmicos erigidos

\footnotetext{
${ }^{13} \mathrm{Ou}$ o aumento das finanças especulativas e ponzi, conforme a tipologia dos fluxos de caixa, proposta por Minsky (2008), que classifica em três situações possíveis: hedge, especulativo e ponzi. "The existence of a large component of positions financed in a speculative or a Ponzi manner is necessary for financial instability" (Minsky, 2008, p. 232).

14 "The stability of the economy depends upon the way investment and positions in capital assets are financed. It will be argued that instability is determined by mechanisms with the system, not outside it;
} 
historicamente que são autorreferenciados e interconectados: o enquadramento neoliberal (globalização, flexibilidade do mercado de trabalho, abandono do pleno emprego, Estado mínimo), mudanças na estrutura e operação dos mercados financeiros (facilidade do crédito, desregulamentação e inovações financeiras), comportamento corporativo (alinhamento com a hipótese de maximização de dividendos) (Palley, 2007). Nas palavras de Reich (2007) o "supercapitalismo" (capitalismo de livre mercado) passa a triunfar enquanto o "capitalismo democrático" passa a enfraquecer-se.

A globalização financeira e a desregulamentação dos mercados financeiros favoreceram a liberalização internacional do fluxo de capitais e são apontados por Aglietta (2004), Aglietta e Rebérioux (2005) e Stockhammer (2010) como os principais incidentes que irromperam no cenário financeiro com novas instituições (i.g., shadow banks) e instrumentos (i.g., derivativos, securitização). Segundo Tavares (1998, p. 66), o desenvolvimento das relações de crédito, novas instituições e instrumentos financeiros são capazes de permitir a "valorização contábil do dinheiro pelo dinheiro", possibilitando que a parte "ativa" (real) do dinheiro (aquele da esfera produtiva) diminua e o capital financeiro fictício crie, cada vez mais, riqueza abstrata a partir da sua parte "passiva" (irreal) (Tavares, 1998).

O propósito dessas novas instituições e novos instrumentos era pulverizar o risco das atividades financeiras, tornando o sistema financeiro mais robusto ${ }^{15}$ (Aglietta, 2008).

De acordo com Belluzzo (2009), mais do que em qualquer outro período do capitalismo, as políticas monetárias estão severamente constrangidas pelas tensões e desequilíbrios que nascem dos mercados financeiros. Os efeitos sobre o nível de atividade são, portanto, mais desfavoráveis nesses ciclos comandados pela dinâmica dos mercados financeiros. Para evitar crises trágicas como as de 1929 surgiram o Big Bank e o Big Government (Braga, 2009) e, "na ausência de um socorro tempestivo do emprestador de última instância, a propagação do pânico pode levar à ruptura do sistema de pagamentos e à corrida bancária" (Coutinho \& Belluzzo, 1998). Portanto, a relação entre Estado e mercado mudou. Atualmente o que se tem verificado é que há uma forte tendência para mudanças súbitas de opinião e polarização das expectativas, gerando ainda mais instabilidade no sistema (Coutinho \& Belluzzo, 1998). Keynes (1985) demonstra preocupação com a importância das repentinas mudanças na opinião pública e no estado de confiança:

O estado da expectativa a longo prazo, que serve de base para as nossas decisões, não depende, portanto, exclusivamente do prognóstico

our economy is not unstable by mechanisms because it is shocked by oil, wars, or monetary surprises, but because of its nature" (Minsky, 2008, p. 172).

${ }^{15} \mathrm{O}$ caso da titularização (securitização), por exemplo, transforma empréstimos em títulos financeiros a partir de pooling, offloading e tranching. "An investment bank buys loans from those who have issued them. The result is a pool of homogeneous or heterogeneous streuctured credit. [...] The loans in the pool are taken out of the investment bank's balance sheet to be registered in special" structures [...]. These structures are, in fact, equivalent to unregulated and unsupervised money market banks. [...] The securities are issued in structured tranches according to their level of risk” (Aglietta, 2008, s.n.). 
mais provável que possamos formular. Depende, também, da confiança com a qual fazemos este prognóstico [...].Se esperarmos grandes mudanças, mas não tivermos certeza quanto à forma precisa com que tais mudanças possam ocorrer, nosso grau de confiança será, então, fraco. (Keynes, 1985, p. 110) [...]

O mercado estará sujeito a ondas de sentimentos otimistas ou pessimistas, que são pouco razoáveis e ainda assim legítimos na ausência de uma base sólida para cálculos satisfatórios. (Keynes, 1985, pp. 110,113)

A divergência de opiniões em uma economia monetária é fundamental para o funcionamento da economia, evitando-se assim o "efeito manada".

Normativamente o Estado tem o papel de prover a recuperação da economia praticando políticas de emprego e renda, no entanto, o que se tem verificado, nessa atual fase do capitalismo, é uma preocupação macroeconômica com a deflação de ativos financeiros. "Verificou-se ao longo dos últimos tempos um Estado cada vez menos da macroeconomia do emprego e da renda (nesse caso é o Estado mínimo, vale o liberalismo) para ser um Estado da macroeconomia da riqueza financeira (nesse caso, o Estado máximo, interventor)" (Braga, 2009, p. 93). Mesmo preocupando-se com a riqueza financeira e praticando políticas para evitar a deflação desses ativos, o Estado tem tido dificuldades em praticar políticas fiscais e monetárias para sanar um sistema financeiro tão grande e complexo.

Historicamente, esse momento é interpretado por Duménil e Lévy (2003) como a "segunda hegemonia da finança" (neoliberalismo) cuja raiz encontra-se na "primeira hegemonia da finança" (do fim do século XIX à crise de 1929), as quais foram separadas pelo interregno keynesiano (do New Deal ao fim dos anos 1970). Os elementos que estão presentes em ambos os períodos são a revolução técnica-organizacional (dos sistemas taylorista e fordista, ou, na linguagem de Aglietta (2004), managerial capitalism, para o enfoque dos acionistas embebido em inovações de comunicação e informação) e uma explosão de mecanismos monetários e financeiros e de rendas financeiras. Para Reich (2007) esse é o momento de triunfo do "supercapitalismo".

Seguindo as ideias, sobretudo de Keynes e de Marx, considera-se que os ciclos de valorização da riqueza é que determinam o funcionamento do sistema capitalista, ou seja, que as decisões dos agentes não são guiadas para satisfazer necessidades humanas, mas sim para valorizar o capital. Assim, assume um mecanismo de dominância financeira sobre o produtivo, que se manifesta pela lógica de valorização patrimonial dos agentes, em que a demanda efetiva se apresenta como um subproduto dessas decisões de alocação da riqueza. Dentro desse contexto, considera que uma característica distintiva das nossas economias é que são economias monetárias, em que a criação de crédito desempenha um papel fundamental. Assim, o sistema financeiro pode gerar, endogenamente, meios de financiamento, independentemente dos recursos reais subjacentes a apoiá-los, portanto, esse sistema pode ser considerado "altamente elástico", sendo que a expansão do volume de financiamento pode ser desconectada da capacidade produtiva da economia. Dessa maneira, as instituições de crédito podem facilitar trocas e transa- 
ções no lado real da economia (por exemplo, pelos sistemas de compensação que facilitam o pagamento de dívidas). Porém, elas também são inerentemente instáveis, sobretudo quando o crédito é canalizado para a circulação financeira com o intuito puramente especulativo.

O processo de financeirização e desregulamentação, descrito acima, somado com a redução da lucratividade no setor produtivo, levou a uma maior exposição ao risco por parte dos agentes. Em termos minskyanos, a passagem da posição hedge para especulativo e de especulativo para ponzi. Ferguson $(2008$, p. 4) aponta que em 2006, as vésperas da crise, o produto mundial estava em torno de US\$ 47 trilhões, enquanto a capitalização dos mercados acionários era de US\$ 51 trilhões, o valor dos títulos US\$ 68 trilhões, e o dos derivativos US\$ 473 trilhões! O mercado de Credit Default Swaps, inexistente na década de 1980, estava em 2007 próximo a US\$ 600 trilhões. Ou seja, o surgimento (e o crescimento exponencial) de instrumentos novos, mais complexos, muito mais expostos ao risco, em um ambiente, como aponta Minsky (2008), de incerteza crescente.

Portanto, a distinção entre positivo e normativo, como propõe Friedmam, conforme exposto na primeira seção, é artificial. Em um mundo não ergódigo, repleto de incertezas, a construção de um ambiente para reduzi-las, envolve, sim, questões normativas. Nesse aspecto, cabe destacar a visão keynesiana, conforme exposta por Carvalho (2003), de que, sob um contexto de incerteza, é importante criar os instrumentos para reduzi-la. Isso depende diretamente dos valores normativos dos formuladores de políticas.

Keynes reconhece que o que importa, de partida, não é o mundo em si, mas o mundo que é percebido. Sob incerteza, o mundo deve ser criado, não descoberto, como supunham a economia política clássica e neoclássica. [...] Se o futuro deverá ser criado, ele não pode ser conhecido $a$ priori. (Carvalho, 2003, p. 180)

\section{CONSIDERAÇÕES FINAIS}

Se a qualidade de uma teoria é medida pelos termos das previsões que ela faz, cabe questionar o mainstream econômico por não haver previsto a crise. Justamente pelos axiomas desta corrente teórica desconsiderarem a incerteza e a ergodicidade (bem como a não neutralidade da moeda e o papel da preferência pela liquidez), a instabilidade inerente a uma economia monetária de produção não é compreendida adequadamente.

É necessário incorporar à análise econômica elementos keynesianos e pós-keynesianos para compreensão da dinâmica de uma economia financeirizada. Somente é possível compreender o funcionamento dessa economia a partir dos pressupostos da incerteza e da não ergodicidade, algo que não é possível a partir da teoria neoclássica e seus axiomas restritivos.

É necessário retomar a compreensão de que a economia é uma ciência social par excellence, e que métodos tomados das ciências naturais não produzem resul- 
tados adequados para o entendimento dos fenômenos econômicos. Mesmo a adoção de modelagem formal elegante não garante a compreensão dos processos econômicos em ambientes complexos, pela incompreensão do mecanismo de tomada de decisão em um ambiente de incerteza.

Em resposta ao questionamento lançado no início deste ensaio, se a teoria neoclássica teria perdido sua capacidade de realizar previsões, fica claro que estas somente são possíveis em um ambiente de probabilidade objetiva. Na medida em que a economia aprofunda o processo de financeirização e os agentes passam a ter um comportamento mais especulativo e ponzi, previsões ergódigas perdem efetividade, uma vez que uma série de eventos totalmente imprevisíveis leva a alteração do mercado financeiro, como ocorreu na crise de 2008.

Ao não reconhecer alguns princípios que melhor descrevem a dinâmica do capitalismo, como os princípios da não ergodicidade e da incerteza keynesianas, o mainstream foi incapaz de prever a crise de 2008 e é incapaz de prever outras crises econômicas. Devido ao tratamento das séries econômicas como estacionárias, os indivíduos acreditavam que os resultados verificados nos anos anteriores à aparição da crise se repetiriam continuamente num futuro que era a continuação lógica do presente. O custo de ignorar a história e os ensinamentos de Keynes e de outros economistas heterodoxos foi lançar a economia mundial a um período de crise.

Como salientou Davidson (1991), é necessário ter cautela ao adotar as premissas neoclássicas. De acordo com esse autor, os economistas não deveriam ter a pretensão de explicar mais do que a disciplina pode entregar.

Economists should be careful not to claim more for their discipline than they can deliver. Lucas and Sargent's belief (1981, pp. xi-xii), that in "some circumstances" the world is probabilistic, or the expected utility theorists presumption that future prospects can be completely ordered, tends to lead to the argument that individuals in free markets do not make persistent errors and they know better than the government how to judge the future. Basing general policy rules on these assumptions can result in disastrous advice for governmental officials facing situations where private sector economic decision makers believe that the future cannot be reliably predicted from past experience. (Davidson, 1991, p. 142)

Como lição positiva da crise, fica o fato do maior destaque teórico para abordagens keynesianas, minskyanas e heterodoxas de maneira geral. Resta esperarmos que essa mudança leve a alterações na formulação de política econômica nos moldes das correntes discutidas acima e que se repensem os fundamentos sobre os quais a teoria econômica tradicional foi construída.

\section{REFERÊNCIAS BIBLIOGRÁFICAS}

AGLIETTA, M. (1998) “The future of capitalism”, in CORIAT, B. et al. (ed.). The Hardship of Nations: Exploring the Paths of Modern Capitalism (new horizons in institutional and evolutionary economics). Cheltenham (UK): Edward Elgar Publisher. 
(2004) Macroeconomia Financeira: Mercado Financeiro, Crescimento e Ciclos. São Paulo: Edições Loyola.

; REBÉRIOUX, A. (2005) Corporate Governance Adrift: A Critique of Shareholder Value. Cheltenham (UK): Edward Elgar Publisher.

BELluZZO, L. G. (2009) Os Antecedentes da Tormenta: Origens da Crise Global. São Paulo: Unesp. ; TAVARES, M. C. (1980) "Capital financeiro e empresa multinacional", Temas de Ciências Humanas, n. 9, pp.113-124.

BLAUG, Mark (1985) Economic Theory in Retrospect. Cambridge: Cambridge University Press.

BRAGA, J. C. S. Temporalidade da Riqueza: Teoria da Dinâmica e Financeirização do Capitalismo. Campinas (SP): UNICAMP. IE, 2000. (Coleção Teses).

(2009) "Crise sistêmica da financeirização e a incerteza das mudanças”, Revista Estudos Avançados, 23 (65).

CARVALHO, F. C. (1989) "Fundamentos da escola pós-keynesiana: a teoria de uma economia monetária”, in AMADEO, E. (ed.). Ensaios Sobre Economia Política Moderna. São Paulo: Marco Zero. (1992) Mr. Keynes and the Post Keynesians: Principles of Macroeconomics for a Monetary Production Economy. Aldershot: Elgar.

(1996) "Sobre a centralidade da teoria da preferência pela liquidez na macroeconomia pós-keynesiana”, Ensaios FEE, v. 17, n. 2, pp. 42-77, 1996.

(2003) "Características essenciais do método de Keynes na teoria geral”, in CORAZZA, G. (org.). Métodos da Ciência Econômica. Porto Alegre: Editora da UFRGS.

CLOWER, R., ed. (1969) Monetary Theory. London: Penguin.

CORAZZA, G., org. (2003) Métodos da Ciência Econômica. Porto Alegre: Editora da UFRGS.

COUTINHO, L.; BELLUZZO, L. G. (1998) "Financeirização da riqueza, inflação de ativos e decisões de gasto em economias abertas”, Economia e Sociedade, v. 7, n. 2 (11), pp. 137-150.

CHESNAY, F. (2003) “A 'nova economia': uma conjuntura própria à potência econômica estadunidense”, in CHESNAIS, F. et al. Uma Nova Fase do Capitalismo? São Paulo: Editora Xamã.

DAVIDSON, P. (1991) "Is probability relevant for uncertainty? A post keynesian perspective.", The Journal of Economic Perspectives, v. 5, n. 1.

(2009) The Keynes Solution: The Path to Global Economic Prosperity. New York: Palgrave MacMillan.

(2011) John Maynard Keynes. São Paulo: Actual.

(2012) "Is economics a science? Should economics be rigorous?", Real-World Economics Review, n. 59.

DUAYER, M.; MEDEIROS, J. L.; PANCEIRA, J. P. (2001) “A miséria do instrumentalismo na tradição neoclássica", Estudos Econômicos, v. 31, n. 4, pp. 723-783, out.-dez.

DUMÉNIL, G.; LÉVY, D. (2003) “Superação da crise, ameaças de crises e novo capitalism”, in CHESNAIS, F. et al. Uma Nova Fase do Capitalismo? São Paulo: Editora Xamã.

FERGUSON, N. (2008) The Ascent of Money: A Financial History of the World. New York: Penguin

FERRARI FILHO, F.; ARAÚJO, J. P. (2000) “Caos, incerteza e teoria pós-keynesiana”, Ensaios FEE, Porto Alegre, v. 21, n. 2.

FERRARI FILHO, F.; CONCEIÇÃO, O. (2001) A noção de incerteza nos pós-keynesianos e institucionalistas: uma conciliação possivel? XXIX Encontro Nacional de Economia, 2001.

FRIEDMAN, M. (1953) “The methodology of positive economics", in FRIEDMAN, M.. Essays in positive economics. Chicago: University of Chicago Press.

FRACALANZA, P. S.; RAIMUNDO, L. C.; MIRANDA, T. (2009) A corporação contemporânea e o regime de acumulação liderado pela finança. In: ANAIS do XIV Encontro Nacional de Economia Política, São Paulo.

GALBRAITH, J. K. (1991) La Breve Historia de la Euforia Financiera. Barcelona: Ariel.

HAUSMAN, D. (1992) "Why look under the hood.", in HAUSMAN, D. Essays on philosophy and economic methodology. Cambridge: Cambridge University Press.

HUTCHISON, T. (1965) The Significance and Basic Postulates of Economic Theory. New York: Augustus M. Kelley. 
KEYNES, J. M. (1921) A Treatise on Probability. London: MacMillan and Co. (1933) A Monetary Theory of Production. Collected Writings, XIII: 408-411. (1937) “The general theory of employment”, The Quarterly Journal of Economics, February. (1985) A Teoria Geral do Emprego, do Juro e da Moeda. São Paulo: Nova Cultural.

KNIGHT, F. (1921) Risk, Uncertainty and Profit. Cambridge: The Riverside Press. (1940) "What is truth" in economics? Journal of Political Economy, v. 48 (1): 1-32.

LAWSON, T. (1988) "Probability and uncertainty in economic analysis", Journal of Post Keynesian Economics. Vol. 11, $\mathrm{n}^{\circ} 1$.

(1997) Economics and Reality. London: Routledge.

LISBOA, M. B. (1997) “A miséria da crítica heterodoxa. Primeira Parte: Sobre as críticas”, Revista de Economia Contemporânea, $\mathrm{n}^{\circ}$ 2, julho/dezembro.

(1998) "A miséria da crítica heterodoxa. Segunda Parte: Método e equilíbrio na tradição neoclássica", Revista de Economia Contemporânea, $\mathrm{n}^{\circ} 3$, janeiro/junho.

MACHLUP, F. (1994) “On indirect verification”, in HAUSMAN, D. (org.). The Philosophy of Economics: An Anthology. $2^{\text {nd }}$ edition, Cambridge: Cambridge University Press.

MARQUES, R. M.; NAKATANI, P. (2009) O Que é Capital Fictício e Sua Crise. São Paulo: Editora Brasiliense.

MARX, K. (1985) O Capital. São Paulo: Abril Cultural, Volume III, Livro II.

MAZZUCCHELLI, F. (2008) "A crise em perspectiva: 1929 e 2008", Novos Estudos CEBRAP, n. 82.

MINSKY, H. P. (2008) Stabilizing an Unstable Economy. New York: McGraw Hill.

(1996) "Uncertainty and the institutional structure of capitalist economies", Journal of Economic Issues, v. XXX, n. 2, pp. 357-368.

MOLLO, M. L. R. (2011) "Capital fictício, autonomia produção-circulação e crises: precedentes teóricos para o entendimento da crise atual”, Economia (Brasília), v. 12, pp. 475-496.

NORTH, D. (2005) Understanding the Process of Economic Change. Princeton: Princeton University Press.

PALLEY, T. (1993) "Uncertainty, expectations, and the future: if we don't know the answers, what are the questions?", Journal of Post Keynesian Economics, 1-20.

(2007) "Financialization: what it is and why it matters", The Levy Economics Institute Working Paper No. 525, 2007.

REICH, R. (2007) Supercapitalism: the transformation of business, democracy, and everyday life. Knopf Publisher.

SAMUELSON, P. (1969) "Classical and neoclassical theory”, in CLOWER, R. (ed). Monetary Theory. London: Penguin.

SIMON, H. (1986) "Rationality in psychology and economics", The Journal of Business, vol. 59, No. 4, part 2.

SOLOW, R. (1985) "Economic history and economics", The American Economic Review. v. 75, n. 2.

STOCKHAMMER, E. (2000) "Financialization and the slowdown of accumulation", Viena University of Economics and Business Administration, Working Paper No. 14, 2000.

(2010) "Financialization and the global economy", Political Economy Research Institute. University of Massachusetts Amherst. Working Paper No. 240.

(2012) "Financialization". In TOPOROWSKI, J.; MICHELL, J.. Handbook of Critical Issues in Finance. Cheltenham: Edward Elgar.

TAVARES, M. C. (1998) Ciclo e crise: o movimento recente da industrialização brasileira. Campinas, Instituto de Economia, 1998.

TOPOROWSKI, J.; MICHELL, J. (2012) Handbook of Critical Issues in Finance. Cheltenham: Edward Elgar.

VASAPOLLO, L.; ARRIOLA, J. (2010) Crisis o big bang: La crisis sistémica del capital ¿qué, cómo y para quién? La Habana: Instituto Cubano del Libro, 2010. 